\title{
EL PROBLEMA DEL DERECHO A LA IDENTIDAD EN EL CÓDIGO CIVIL Y COMERCIAL DE LA NACIÓN
}

\author{
JOSÉ MIGUEL CRUZ* \\ UNIVERSIDAD CATÓLICA DE SANTIAGO DEL ESTERO \\ SEDE JUJUY \\ ARGENTINA
}

Lo más dificil de aprender en la vida es aprender qué puente hay que cruzar y qué puente hay que quemar.

Bertrand Russell. 


\begin{tabular}{c}
\hline JOSÉ MIGUEL CRUZ \\
$\mathbf{2 4 8}$ EL PROBLEMA DEL DERECHO A LA IDENTIDAD EN EL CÓDIGO CIVIL Y COMERCIAL DE LA NACIÓN \\
Pags. 247 - 259
\end{tabular}

Recibido: 25/04/2015

\section{RESUMEN}

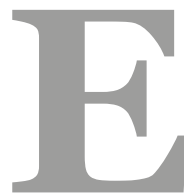

ste trabajo ha visto la luz con la modesta intención de resaltar uno de los desaciertos que contiene el código civil y comercial en materia de filiación e identidad: la adopción de un sistema que restringe el acceso a la información identificatoria del donante al concebido por las técnicas de reproducción humana asistida. Con apoyo en la legislación y la jurisprudencia pertinente es que se propone una eventual reforma del art. 564 adoptando un régimen más favorable al concebido por las técnicas de referencia en concordancia con el sistema de derechos humanos.

Palabras claves: derecho de familia; filiación; identidad; técnicas de reproducción humana asistida; código Civil y Comercial; artículo 564.

\section{PRESENTACIÓN}

Originalmente, Vélez reguló solamente la filiación por naturaleza y, recién en el año 1948, ingresó al ordenamiento jurídico argentino la figura de la adopción a través de la ley 13.252, inaugurando una nueva fuente de filiación. A estas dos fuentes de filiación, actualmente, se agrega una tercera: la derivada de las técnicas de reproducción asistida (en adelante TRHA).

Ahora bien, la cuestión de las TRHA no representa una novedad de estos días. En efecto, el primer registro de una inseminación artificial con donante data del año 1.884 en Estados Unidos. Este hecho tuvo lugar en el Estado de Filadelfia y fue llevada a cabo por William Pancoast en el “Jefferson Medical College”. Según se recuerda, en la ocasión, un adinerado comerciante le expuso al profesional su imposibilidad para procrear y éste último vio una oportunidad para probar un nuevo procedimiento. En virtud del mismo, la esposa del paciente fue anestesiada y, ante una audiencia de estudiantes de medicina, fue inseminada y nueve meses más tarde nació un niño ${ }^{1}$. Desde este hecho en particular y a la par del desarrollo de las TRHA por la ciencia médica, largo ha sido el camino hacia la inclusión de las mismas en el nuevo código civil y comercial argentino.

Fue con la llegada del anteproyecto de código civil y comercial 2012 que el tema de las TRHA cobró, una vez más, protagonismo en la escena jurídica del derecho de familia. En efecto, mucho se debatió al respecto y tras muchas idas y vueltas se fue arribando a la conclusión que hoy vivimos, la sanción y promulgación del entonces proyecto de código civil y comercial

\footnotetext{
*Estudiante, Universidad Católica de Santiago del Estero Departamento Académico San Salvador de Jujuy.

${ }^{1}$ Hard AD, Artificial impregnation. Med World, 1909, p 27-163. Citado en: MENDIOLA OLIVARES Jaime Esterilidad y Reproducción Asistida: Una perspectiva histórica. Revista Iberoamericana de fertilidad vol. 22 - № 1. Cartagena (España), 2005. Pág. 16.
} 
que se transformó hoy en día en ley vigente -desde el pasado primero de agosto- transformando para siempre algunos paradigmas, aggiornando varias instituciones e incorporando varias novedades, entre ellas, las TRHA.

Años atrás, ya habíamos presenciado algún intento de regular la delicada cuestión de las TRHA. Fruto de esa intención fue la sanción de la ley 26.862. Ley que fuera criticada en su momento por no ser una ley de "regulación integral" sino una "ley de acceso a la cobertura médica a las técnicas" a las cuales definiría como todos aquellos procedimientos y técnicas realizados con asistencia médica para la consecución de un embarazo. Fue esta ley junto a su decreto reglamentario los que ya habían preparado el camino al debate objeto del presente.

Hoy en día, la inclusión de las TRHA en el código civil y comercial trae consigo un gran desafío en materia de derechos personalísimos, en particular, en relación al derecho a la identidad de las personas nacidas a partir de material genético donado por un tercero. Alrededor de este hecho, surgen grandes interrogantes que el código civil y comercial ha intentado responder; empero, ¿Cómo se ha regulado esta cuestión? ¿Ésta regulación es concordante con la defensa que reclama el derecho a la identidad dentro del derecho argentino? Las páginas siguientes harán el intento de despejar estas dudas.

\section{IDENTIDAD Y FILIACIÓN: UN GRAN INTERROGANTE}

En su momento, muchos se preguntaron si era necesaria o no la incorporación de una tercera fuente filial al nuevo código civil y comercial. Sin embargo, la realidad ha mostrado que estas técnicas sí ameritaban la apertura de un nuevo capítulo en el campo del derecho de familia. De hecho, las técnicas ya se llevan a cabo en nuestro país ${ }^{2}$ y la ausencia absoluta de una regulación de las TRHA, en el contexto de los tiempos que corren, se presentó como una demanda del mismo ordenamiento jurídico a los efectos de dar respuesta a los vacíos legales e imponer los límites éticos a la realización de las TRHA. Recordemos que, aunque el código ha receptado estas técnicas regulando algunos aspectos y aunque se haya regulado la cobertura, no hay al día de la fecha una norma integral que regule específicamente la cuestión. ${ }^{3}$

De esta manera, en la regulación actual ha quedado en el olvido el art. 240 del código de Vélez que establecía: "La filiación puede tener lugar por naturaleza o por adopción. La filia-

\footnotetext{
${ }^{2}$ Datos estadísticos elaborados por la Red Latinoamericana de Reproducción Asistida (REDLA), difundidos en 2012, informan que en el país hay un total de 25 centros de salud en los que se realizan TRHA. Puede consultarse on line: www.jbra.com.br/media/ html/JBRA1081.html

${ }^{3}$ Sin embargo, ya hay un proyecto aprobado por la cámara de diputados que ha sido enviado al senado como complementario del código civil y comercial, por el cual se regulan las técnicas de reproducción humana asistida y la protección de los embriones no implantados.
} 
ción por naturaleza puede ser matrimonial o extramatrimonial. La filiación matrimonial y la extramatrimonial, así como la adoptiva plena, surten los mismos efectos conforme a las disposiciones de este Código". A partir de la entrada en vigencia del nuevo código civil y comercial, se dispone en la primera parte del nuevo art. 558: "La filiación puede tener lugar por naturaleza, mediante técnicas de reproducción humana asistida, o por adopción”. De esta manera, las TRHA se han consagrado como tercera fuente filial. Ahora bien, dentro de éstas, son las técnicas de carácter heterólogas las que abren la puerta a la posibilidad de que las personas nacidas por donación de material genético de tercero se pregunten por la identidad del donante del material que posibilitó su nacimiento, más precisamente, su concepción.

Es allí cuando surge la preocupación por la protección del derecho a la identidad del concebido por estas técnicas. En efecto, si asumimos que la identidad del donante como dato genético completa la identidad de la persona concebida por las TRHA, es importante destacar el texto del art. 563 del nuevo código, el cual se nos presenta en los siguientes términos: "La información relativa a que la persona ha nacido por el uso de técnicas de reproducción humana asistida con gametos de un tercero debe constar en el correspondiente legajo base para la inscripción del nacimiento”. Hay que reconocer que ésta disposición guarda coherencia con lo acontecido jurisprudencialmente en el año 2014, año en que a los fines de garantizar la posibilidad de ejercicio efectivo del derecho reconocido en el art. 8 de la Convención de los derechos del Niño -referente a la identidad-, se hizo lugar parcialmente a la demanda de amparo entablada contra el Estado Nacional, ordenando a éste por sentencia de la Sala V de la Cámara Nacional en lo Contencioso Administrativo y Federal a que a través del Ministerio de Salud de la Nación, arbitre los medios que estime más convenientes a fin de preservar de manera efectiva la información relativa a la donante de los óvulos utilizados para llevar a cabo el procedimiento de fertilización asistida, ya sea mediante el dictado de un acto administrativo de alcance particular o general, sin dar acceso a ella a la parte interesada y exclusivamente con el objeto de ser utilizada en las condiciones y modalidades que oportunamente establezca el Congreso de la Nación al dictar la reglamentación legal correspondiente. ${ }^{4}$

Este precedente ha consagrado la necesidad de asegurar la guarda de esta información no solo en el seno de los centros donde se llevan a cabo las TRHA por donación de material genético sino en el ámbito del Estado Nacional mediante el Ministerio respectivo. Es así que puede decirse que lo normado en el art. 563 representa un acierto a los efectos de la tutela del derecho a la identidad del concebido por las TRHA, pero surge otra pregunta: ¿es suficiente? Respondiendo a este interrogante, se ha interpretado que conforme la letra del art. 563, parecería que abastece el derecho a la identidad de la persona nacida mediante TRHA el hecho de que conste en el legajo de inscripción que fue concebido de esa manera, con la utilización 
de material genético de una tercera persona[...] Pero de la lectura de la norma citada, sólo esto sería suficiente para la ley para el goce del derecho referido, solución que no parecería idónea ya que esto solo no responde todos los interrogantes que pueda tener una persona que desea conocer su procedencia ${ }^{5}$. En efecto, el primer gran paso en la defensa del derecho a la identidad se cumple (esto es, el resguardo de la información relativa al procedimiento).

No obstante el acierto del 563, una norma que llama poderosamente la atención en el tema que nos interesa, es la del art. 564 que, en los términos planteados, representa un error. En efecto, en el art. 564 se hace referencia al contenido de la información a la que puede acceder una persona nacida por las TRHA habiéndose dispuesto que: "A petición de las personas nacidas a través de estas técnicas, puede: a) obtenerse del centro de salud interviniente información relativa a datos médicos del donante, cuando es relevante para la salud, b) revelarse la identidad del donante, por razones debidamente fundadas, evaluadas por la autoridad judicial por el procedimiento más breve que prevea la ley local”. Como se desprende de la lectura del art. 564, se supedita el íntegro goce del derecho a la identidad del concebido por las TRHA a un pronunciamiento judicial que, si bien es a través del procedimiento más breve que prevea la ley local, ya representa un obstáculo importante. Hay que decir que si bien no hay una privación absoluta del derecho a conocer los orígenes (dentro del derecho a la identidad), sí hay una restricción que representa un importante obstáculo para los concebidos por las técnicas de referencia. De tal manera que conservar la información que hace a la identidad del concebido por TRHA carecería de utilidad si ésta le es privada o negada a la persona interesada en conocer sus orígenes. Ésta novedad en materia de filiación e identidad es la que nos obliga a preguntarnos otra vez: ċes adecuada la protección del derecho a la identidad en el código civil y comercial? Habrá que evaluar esta pregunta de acuerdo a lo que se entiende por derecho a la identidad.

\section{EL ARTÍCULO 564 A LA LUZ DEL "DERECHO A LA IDENTIDAD”}

En opinión del Comité Jurídico Interamericano, "el derecho a la identidad es consustancial a los atributos y a la dignidad humana. Es en consecuencia un derecho humano fundamental oponible erga omnes como expresión de un interés colectivo de la Comunidad Internacional en su Conjunto que no admite derogación ni suspensión en los casos previstos por la Convención Americana sobre Derechos Humanos”. Siendo así, puede decirse que a una persona que desea

\footnotetext{
${ }^{5}$ ANGELOZZI Lucía Belén Alonso, Las técnicas de reproducción humana asistida heterólogas y el derecho a la identidad: su regulación en el nuevo Código Civil y Comercial de la Nación. Ponencia presentada en las "Jornadas sobre el Nuevo Código Civil y Comercial (preparatorias de las XXV Jornadas Nacionales de Derecho Civil) Monte Hermoso, 5 y 6 de diciembre de 2014. Disponible on-line: jndcbahiablanca2015.com/?cat=7

${ }^{6}$ Opinión aprobada por el Comité Jurídico Interamericano sobre el Alcance del Derecho a la Identidad (OEA); agosto de 2007; número 12.
} 
completar el conocimiento de su identidad no le es suficiente el hecho de conocer que ha sido concebido por estas técnicas (ya amparada en el art. 563). Una adecuada protección del derecho a la identidad demanda el conocimiento de la identidad del donante del material con que ha sido concebido. En este sentido, además, cabe recordar que en las pasadas XXIII Jornadas Nacionales de Derecho Civil llevadas a cabo en la Universidad Nacional de Tucumán en el año 2011, en la comisión de familia, se arribó a siguiente conclusión: los niños tienen derecho a que, en la medida de lo posible, se respete la unidad de todos los estratos de su identidad (genética, biológica, familiar, social, y jurídica).

La identidad del donante en las TRHA representa un "dato" que ciertamente forma parte del derecho a la identidad del sujeto de derecho. Es más, el hecho de conocer este "dato" completa el ejercicio del derecho a conocer los orígenes y en consecuencia el derecho a la identidad y permite afirmar que más que un "dato", se trata una parte del pasado de la persona, de una porción de su génesis a cuyo acceso debe tener derecho irrestrictamente. Con razón se ha dicho que la identidad personal es el "conjunto de atributos y características que permiten individualizar a la persona en sociedad. Es todo aquello que hace que cada cual sea uno mismo y no otro. Esta identidad se despliega en el tiempo y se forja en el pasado desde el instante mismo de la concepción donde se hallan sus raíces y sus condicionamientos pero traspasando el presente existencial, se proyecta al futuro". Precisamente, entre aquel conjunto de características, la identidad de los donantes en las técnicas de referencia cobra un valor primordial por cuanto su conocimiento importa conocer la "raíz" de la identidad para una adecuada proyección al futuro.

También es menester recordar que según se desprende del Preámbulo de la Constitución de la Organización Mundial de la Salud (OMS), la salud es un "estado de completo bienestar físico, mental y social, y no solamente la ausencia de afecciones o enfermedades”. En consecuencia, puede uno preguntarse si la sola invocación del derecho a la identidad sería considerada "razón debidamente fundada" a los efectos de que le sea revelada la identidad del donante. Estimo que sí. Máxime si el desconocimiento de la identidad del donante para los concebidos por estas técnicas puede llegar a implicar una afección a aquel completo bienestar que es la salud. Entiendo que es poco probable que se niegue el acceso a la información a las personas concebidas por las TRHA ya que no es fácil concebir sólidos argumentos en contra del pedido de información que haga el interesado.

No obstante, ante la pregunta obligada y recurrente: "¿Las personas que nazcan debido a la donación de esperma van a poder conocer su identidad?”, se ha argumentado que: "Hay que diferenciar. Información no identificatoria, como datos de salud, siempre van a poder tener. Pero para conocer el nombre, apellido y demás (del donante) siempre tiene que haber un fundamento y un derecho que esté comprometido. De lo contrario, la gente no donaría y estos pro- 
pios chicos no hubieran nacido. Si estos chicos nacen, es porque alguien donó. Si la donación no es anónima o no tiene cierta restricción, la gente no va a donar y el sistema no va a funcionar. Uno tiene que sopesar derechos". ${ }^{8}$

Del art. 564 y del argumento referido en el párrafo anterior, en relación al derecho a la identidad, como lo he venido anticipando, se desprende una injustificada restricción en perjuicio del concebido por las TRHA con material genético de terceros. En efecto, para acceder a la información identificatoria del donante, ésta deberá ser solicitada mediante un procedimiento ante el órgano jurisdiccional. Solo en el caso de que el interesado acredite "razones debidamente fundadas", podría acceder al conocimiento de la identidad del donante. Considero que una correcta interpretación del texto así planteado se traduce en el hecho de que, en todo caso, la sola invocación del derecho a la identidad tendría que ser suficiente razón para acceder a la identidad del donante. Esto en razón de que éste último comparte la identidad genética-biológica con el concebido a partir de su material genético y ese "dato", como ya se ha dicho, forma parte de la "identidad" a la que, insisto, se debe poder acceder de manera irrestricta.

En este sentido, es dable recordar que -en relación al derecho a la información en este tipo de procedimientos- en el mundo, se reconocen sistemas que reconocen la protección del anonimato absoluto del donante ${ }^{9}$ en contraposición a aquellos sistemas que prohíben este tipo de técnicas o permiten en todos los casos el acceso a la información identificatoria del donante ${ }^{10}$. Como se adelantó, el código adopta una solución "intermedia" entre el anonimato absoluto y el levantamiento total del anonimato. Se afirma que de esta manera se garantiza, por un lado, la existencia de donantes, y por el otro, el derecho del niño nacido por TRHA a conocer su origen genético ${ }^{11}$, todo ello a la luz del principio de proporcionalidad. Sin embargo, esta solución no está libre de objeciones.

En primer lugar, de los argumentos de esta tesis intermedia se desprende la presunción de que si el donante sabe que sus datos van a ser revelados al concebido por su material genético no donaría. Pero cabe resaltar que - independientemente de cierta restricción - con este sistema intermedio también van a ser revelados sus datos identificatorios solo que mediante un procedimiento de por medio. Consecuentemente, los donantes deberán ser conscientes de que sus datos no serán revelados en primera instancia pero que podrán ser revelados luego de un procedimiento judicial en el que el interesado deberá acreditar "razones debidamente fundadas" y de tal manera se regularía en atención al derecho a la intimidad - del donante - y al derecho a la

\footnotetext{
${ }^{8}$ Entrevista a la Dra. Marisa Herrera publicada en el Tribuno de Salta el 04-10-2012. "Marisa Herrera: ¿El embrión no implantado en el útero de la madre nunca va a ser persona?". Disponible On-Line: www.eltribuno.info/marisa-herrera-el-embrion-noimplantado-el-utero-la-madre-nunca-va-ser-persona-n208440

${ }^{9}$ Tal el caso de la legislación de Grecia o Dinamarca. Otro ejemplo de este sistema lo representan la ley francesa $94-654$ y la Resolución brasileña del Consejo Federal de Medicina de 1957.

${ }^{10}$ Son ejemplos de este sistema la ley sueca de 1984 (insemination act 1140) y la ley austriaca de reproducción médica asistida $275 / 1992$.

${ }^{11}$ LORENZETTI Ricardo Luis, Código Civil y Comercial de la Nación comentado. Tomo III, Rubinzal Culzoni editores, Santa Fe, 2015, p. 521.
} 
identidad - del concebido por las TRHA con material de terceros - en una suerte de equilibrio a la luz del principio de proporcionalidad. Incluso, se ha admitido que se mantendría el sistema intermedio hasta que se instale una "cultura de donación" y a partir de allí tal vez se podría establecer el libre acceso a la información identificatoria del donante ${ }^{12}$. Empero, estas afirmaciones relucen lo falaz del argumento sobre el que descansa el art. 564. Podría uno animarse a afirmar entonces que lo que se está permitiendo es una restricción en el íntegro goce del derecho a la identidad de los concebidos por las TRHA hasta que se instale tal cultura de donación y recién allí se restablecería el respeto integral del Derecho a la Identidad. ¿Esto es legítimo? Acaso esto ¿no es un juego muy objetable de los derechos en pugna?

Por otro lado, y tomando en cuenta el interés del menor que quiere conocer no solo el medio por el que ha sido concebido sino también la identidad del donante y a la luz del "interés superior del niño” acaso, ¿̇el art. 564 no devendría mínimamente en inconstitucional? Todo por ser contrario a normas internacionales ${ }^{13}$ receptadas mediante el art. 75, inc. 22 en materia de Derechos Humanos. De hecho, la referencia a los instrumentos internacionales no es casual por cuanto la República argentina adhiere a ellos y se ha obligado a respetarlos y cualquier restricción al derecho a la identidad podría considerarse objeto de un reclamo internacional ante la Corte Internacional de Derechos Humanos en caso de cumplirse los requisitos exigidos por dicha entidad.

Ahora bien, para el hipotético caso en que el órgano jurisdiccional considere que el peticionante "no" ha acreditado "razones debidamente fundadas" para conocer la identidad del donante, ¿Qué opciones quedan? Lo lógico sería afirmarse en la existencia de la vía recursiva; empero, ¿cuánto tiempo pasará hasta que un juez decida reconocerle el íntegro ejercicio del derecho a la identidad al concebido por TRHA? ¿Es necesario someter al juicio del órgano jurisdiccional el ejercicio de un derecho personalísimo como el de la identidad? Son estas dudas las que ponen en evidencia que el trámite judicial a los efectos de obtener la información identificatoria no se justifica y representa un obstáculo innecesario para quien pretende conocer una importante parte de su historia de vida. Se trata de una desafortunada novedad para el derecho argentino.

Ahora bien, respecto de los donantes, cabe plantearse si el hecho de permitir que su identidad sea revelada es inconstitucional. Claramente que no; en efecto, son los adultos los que deben tomar razón de la responsabilidad que les compete en cuanto al material genético que están do-

\footnotetext{
${ }^{12}$ KEMELMAJER DE CARLUCCI Aida; HERRERA Marisa y LLOVERAS Nora, Tratado de Derecho de Familia según el código Civil y Comercial de 2014. Tomo II. Rubinzal Culzoni editores. Santa Fe, 2014. Pág. 555

${ }^{13}$ En particular, cabe citar la Convención Internacional sobre los Derechos del Niño, cuyo artículo 8, dispone: "1. Los Estados Partes se comprometen a respetar, el derecho del niño a preservar su identidad, incluidos la nacionalidad, el nombre y las relaciones familiares de conformidad con la ley sin injerencias ilícitas". Respecto a la cuestión de preservar la identidad, es cierto que se asegura la preservación de la identidad a través del guardado de los datos de la persona cuyo material genético se ha utilizado en las TRHA y se trata de una obligación impuesta al Estado. Sin embargo, como lo adelanté, no es suficiente a los efectos de una adecuada tutela del derecho a la identidad y más razón asiste a esta afirmación cuando tomamos en cuenta el restrictivo carácter del art. 564.
} 
nando, incluso en un acto altruista como lo es la donación. El menor concebido por estas técnicas que desea conocer sus orígenes es quien se encuentra en situación de vulnerabilidad digna de tutela y por ende debe primar su derecho a conocer sus orígenes en todo momento. Este derecho se debe imponer siempre por encima del derecho a la intimidad del donante. De tal manera, quien dona, debe ser consiente para qué fines lo hace y cuáles son las consecuencias de tal acto. El donante debe estar informado acerca de que existe la posibilidad real de que su identidad sea revelada a la persona que ha sido concebida por las TRHA y serán los organismos pertinentes los que deberán garantizar que tal información llegue a los donantes. De esta manera, se evitaría que el acto de donación sea realizado sin pleno conocimiento de su accionar.

A partir de los argumentos esbozados en los precedentes párrafos es que corresponde responder al interrogante de si es adecuada la protección del derecho a la identidad del concebido por THRA con un contundente y lamentable "no".

\section{4.- EL ARBITRARIO TRATAMIENTO DEL DERECHO A LA IDENTIDAD}

Luego de emprender el estudio del título $\mathrm{V}$ de filiación y al ingresar al estudio de las normas previstas para la adopción en el título VI del libro II del código, nos encontramos con más razones para afirmar que la protección del derecho a la identidad en el código civil y comercial es insuficiente. Es más, se advierte con mayor claridad el descuido del legislador por la protección de la identidad del niño concebido por TRHA.

En particular, en los artículos 595 y 596 del código, se ha establecido un marco de protección adecuado en relación al derecho a identidad de los niños adoptados. Esta diferenciación ha permitido sostener a algunos autores que lo que se produce a raíz de este tratamiento diferenciado, es la "reaparición de las categorías de hijos". ${ }^{14}$

Las diferencias plasmadas en relación a la tutela del derecho a la identidad entre los niños adoptados y los concebidos por TRHA son evidentes. El derecho a la identidad de los primeros está enumerado entre los principios generales (art. 595 inc. b) pero en relación a los segundos, no hay norma alguna que garantice de manera expresa aquel derecho.

Incluso en relación a la información de que ha sido adoptado o que ha sido concebido mediante TRHA hay una sustancial diferencia. En efecto, el art. 596 establece que: "El expediente judicial y administrativo debe contener la mayor cantidad de datos posibles de la identidad 
del niño y de su familia de origen referidos a ese origen, incluidos los relativos a enfermedades transmisibles" en tanto que en el ya reseñado art. 593 se ha establecido que "la información relativa a que la persona ha nacido por el uso de técnicas de reproducción humana asistida con gametos de un tercero debe constar en el correspondiente legajo base para la inscripción del nacimiento"; de tal manera que resalta la especial atención del legislador en preservar la identidad de los menores adoptados ordenando que se preserve la mayor cantidad de datos posibles a diferencia del 593 en donde no resulta tan claro el deber de preservar con grandes detalles tal información. Así, una sana interpretación del art. 593 nos permite afirmar que en el legajo base se debe resguardar la mayor cantidad de información posible por cuanto ésta hace a la identidad del concebido en tales condiciones.

Una tercera distinción radica en la circunstancia de que el derecho a conocer los orígenes es uno de los principios generales aplicables en relación a los niños adoptados (art. 595 inc. e) no así en relación al concebido por TRHA ya que en virtud del art. 594 se ha supeditado el íntegro ejercicio de este derecho a la decisión del órgano jurisdiccional siempre que existan razones debidamente fundadas o de salud (art. 564). A mayor abundamiento, hay que resaltar que se reconoce al adoptado un mayor grado de legitimación por cuanto se reconoce el derecho al libre acceso al expediente judicial y administrativo en el que se tramitó su adopción. En este sentido, también se permite y se propicia un asesoramiento técnico por disposición judicial a favor del menor adoptado siendo otra exclusividad propia de éste.

Finalmente, cabe apuntar otra injustificada diferencia en orden al deber de hacer conocer los orígenes. Mientras que por aplicación del 596, los adoptantes deben comprometerse expresamente a hacer conocer sus orígenes al adoptado, en relación al concebido por TRHA, no existe norma alguna que erija tal deber quedando en evidencia la desprotección a la que se ha sometido a estos últimos.

Ahora, ¿por qué estas diferencias? ¿Por qué no se han tomado los mismos recaudos en relación a los niños concebidos por TRHA? Tal vez sea porque como se dice en los fundamentos del proyecto: "El dato genético no es el definitivo para la creación de vínculo jurídico entre una persona y el niño nacido mediante el uso de las técnicas en análisis, sino quién o quiénes han prestado el consentimiento al sometimiento a ellas". Sin embargo, no puede negarse que es niño tanto el adoptado, el concebido por medios naturales como el concebido por TRHA y esa sola circunstancia convierte a todo niño en acreedor del mismo marco protectorio, independientemente de la manera en que se haya constituido el vínculo filial con su familia. Toda diferencia no solo es arbitraria sino claramente inconstitucional por aplicación del art. 16 de nuestra Constitución Nacional en cuya virtud todos los habitantes de la nación son iguales ante la ley. 


\section{5.- CONCLUSIONES}

Luego de los cuatro acápites anteriores en los que se ha pretendido indagar acerca del tratamiento del derecho a la identidad de los concebidos por las TRHA es necesario arribar a algunas conclusiones. Estas conclusiones están destinadas a dar una respuesta al problema del derecho a la identidad en el código de reciente nacimiento. Pero ¿cuál es ese problema? Puede decirse que en principio relucen dos grandes inconvenientes. El primero de ellos está representado por la restricción del ejercicio del derecho a la identidad, claramente sesgado por la letra del art. 564 . El segundo entuerto es la injustificada y hasta arbitraria diferencia en la tutela del derecho a la identidad en relación a los concebidos por TRHA.

Respecto del primer asunto, me permito concluir que - de lege lata - el art. 564 debe interpretarse como contrario al respeto por el derecho a la identidad de las personas concebidas por las TRHA y, por ende, la sola invocación del derecho a la identidad debe considerarse como "razón debidamente fundada". De lege ferenda, debe eliminarse todo tipo de restricción al acceso a la información sobre sus orígenes biológicos-genéticos que pueda perjudicar el interés superior del niño de los menores y el derecho humano a la identidad de toda persona humana en concordancia con sistemas como el de Suiza ${ }^{15}$ o Suecia ${ }^{16}$, por ejemplo.

En orden al segundo improperio, la conclusión es que -de lege lata- los principios rectores del marco protectorio del derecho a la identidad previstos en el Título VI deben representar pautas interpretativas a favor de los concebidos por TRHA. La diferencia en relación al derecho a la identidad es irrazonable, injustificada e insostenible. De lege ferenda, deben incorporarse al título de filiación los principios del interés superior del niño, el respeto por el derecho a la identidad y el derecho a conocer los orígenes. Asimismo, debe consagrarse el deber de hacer conocer al concebido por TRHA las condiciones en que ha sido concebido como todos los datos que hacen a la identidad del mismo.

Luego de las precedentes conclusiones, estamos en condiciones de afirmar que el gran problema en relación al derecho a la identidad es el olvido del valor histórico tiene la identidad para la humanidad. ¿Qué sería del ser humano sin la memoria de su pasado? y más aun, ¿qué sería del ser humano sin conocimiento de sí mismo?

Vivimos en un país cuya historia da fe de personas que aún hoy buscan conocer su pasado, construir la historia que impunemente les fuera recortada. El niño concebido por las TRHA no es un producto, es una vida que inaugura la esperanza de un nuevo proyecto para la sociedad y como toda persona humana, merece el respeto propio de su dignidad. La protección de la iden-

\footnotetext{
${ }^{15}$ En Suiza, toda persona tiene acceso a los datos relativos a su ascendencia. Se permite que, a la mayoría de edad, el nacido a partir de semen donado pueda obtener los datos relativos a la identidad del donante.

${ }^{16}$ Conforme el art. 4a de la ley, cuando el nacido de TRHA heterólogas alcance la "madurez suficiente" puede consultar el registro de donación del hospital, con el asesoramiento de la Comisión Asesora de la Seguridad Social.
} 


\begin{tabular}{c}
\hline JOSÉ MIGUEL CRUZ \\
$>\mathbf{2 5 8}$ EL PROBLEMA DEL DERECHO A LA IDENTIDAD EN EL CÓDIGO CIVIL Y COMERCIAL DE LA NACIÓN \\
Pags. 247 - 259
\end{tabular}

tidad de una persona ha de ser máxima. No es legítimo que a merced del deseo reproductivo, el derecho a la identidad haya recibido un injustificado menoscabo.

Es cierto que en la ardua tarea legislativa que desempeñan quienes han sido envestidos con la encomiable responsabilidad de plasmar en un código una serie de leyes para toda una población surgen grandes dilemas al momento de regular; pero no debe olvidarse que también es cierto que la balanza siempre debe estar inclinada a favor del más vulnerable, cualquier claro sentimiento de justicia así lo exige.

También es cierto que la sucesión de normas civiles en materia de derecho de familia a lo largo de la historia del Derecho Argentino nunca ha presentado tantas novedades como las que nos encontramos en el código civil y comercial. Pero aquellas nuevas formas de ver el derecho vienen acompañadas de fuertes desafíos a la luz de la Justicia, guía que ilumina los senderos de los jueces a la hora de juzgar, pero que también llena de luz el camino de los estudiantes quienes también queremos hacer eco de las injusticias de nuestro tiempo en el entendimiento de que los derechos humanos son conquistas que han costado muchas vidas a lo largo de la historia y solo por respeto a esas vidas es que cualquier injustificado menoscabo de derechos resulta condenable.

No por nada se ha conceptualizado a los Derechos Humanos como aquellas facultades que necesitamos ejercer y las situaciones de las que necesitamos gozar para que nuestra vida se desenvuelva de modo compatible con la dignidad y el valor fundamental de la persona hu$m a_{n} a^{17}$. Precisamente, son esas facultades las que necesitamos ejercer. Pero también es nuestra la responsabilidad de bregar por el respeto de aquellas facultades, entre las que descansa el completo ejercicio del derecho a la identidad que, en esta ocasión, se ha visto afectado por un gran problema: una injustificada restricción que no debe ser tolerada. Hemos tolerado muchas restricciones en la historia del ser humano, una más (aun cuando para algunos sea minúscula) no es algo que entre en consideración pero sí en discusión y todo ello con la ilusión de que solo en el respeto por los derechos humanos es que se podrán escribir las memorias más bellas de la historia de la humanidad, memorias donde sus derechos hayan sido una realidad y no solo letra muerta de un texto legal. Y eso también es hacer Derecho. 


\section{CURRICULUM VITAE}

\section{José Miguel Cruz}

Estudiante avanzado de la Universidad Católica de Santiago del Estero, departamento académico San Salvador de Jujuy, provincia de Jujuy. Ha sido distinguido con el Primer Premio a la mejor ponencia en la comisión de estudiantes en las XXIV Jornadas Nacionales de Derecho Civil (Facultad de Derecho UBA 2013) y como mejor orador en el IV Modelo de Naciones Unidas (Universidad Católica de Santiago del Estero 2013). Se desempeña como ayudante de cátedra en la materia Introducción a las Ciencias Políticas desde el año 2011 y se ha desempeñado como ayudante de cátedra de la materia Derecho Civil III durante el año 2014. josemiguel_989@hotmail.com 